\title{
The Deltoid Musculature of the Rodentia
}

\author{
By

\section{R. K. Shrivastava} \\ Zoology Department, University of Saugar \\ Sagar, M. P. India
}

The present paper deals with the description of the deltoid musculature of the Rodentia on a comparative basis with a view to find out possible phylogenetic and adaptive features.

The following dissections were made at the Laboratoire d'Anatomie Comparée, Museum d'Histoire Naturelle, Paris. While the muscles of the shoulder and the arm were studied, the emphasis was mainly on the deltoid muscles to find out their exact extent and the nature.

1-Hydrochaerus capybara

2 Dissections

2-Pteromys sp.

2 ,

3-Arctomys (Marmota) marmota 4 ,

4-Spalax hungaricus 6 ,

5-Dipus hirtipes 4 ,"

6-Eliomys quercinus 4 ,"

7-Ondatra zibetheca 2 ,

8-Atherura africana 2 ,

9-Castor canadensis "

After the dissection the bones were taken out and the insertions were noted. All the diagrams have been drawn from the actual dissections.

\section{Description}

$\mathrm{Cuvier}$ and L a rilla rd, 1849 Castor, Hystrix, Lepus, Hydrochaerus, Cavia)

Pa r s o n s, 1894-1896 (Myoxus, Gerbillus, Cricetus, Cricetomys, Microtus, Myodes, Mus, Rhyzomys, Georychus, Heteromys, Lepus, Aulacodus, Capromys, Myopotamus, Octodon, Hystrix, Sphingurus, Lagostomus, Chinchilla, Dasyprocta, Coelogenys, Cavia, Ceredon, Dipus, Alectaga, 
Sciurus, Pteromys, Spermophilus, Arctomys, Castor) A le z a is, 1900 (Cavia, Mus, Sciurus, Dipus, Lepus, Arctomys)

H o 11 i g e r, 1916 (Thomomys, Lepus, Sciurus, Sylvilagus)

P e te r k a, 1936 (Sciurus, Scalopus, Geomys, Sylvilagus)

W o od \& W h i t e, 1950 (Chinchilla)

1-Hydrochaerus

Origin

1-On the external border of the acromion and the metacromion, the deltoid arises by tendinous fibres.

$2-$ On the inferior extremity of the metacromion and the posterior border of the spine, the deltoid extends upto the half by the fleshy and tendinous fibres and then on one-third more on the spine by aponevrotic fibres.

Insertion - The two fascia unite after a little distance to terminate on the deltoid ridge. The insertion is made by a tendon running from the neck to the middle of the humerus. The mastoido-humeral is inserted in the lower part of the humerus.

-The $\mathrm{m}$. teres minor arises on half of the axillary border of the scapula and is inserted on the great tuberosity, a little far off from the insertion of the $m$. infraspinatus. The origin and the insertion of $\mathrm{m}$. teres minor are both tendinous.

2-Pteromys - The origin of the deltoid on the acromion and the spine are in continuity.

- The deltoid extends on the whole length of the spine. - The clavicular deltoid originates on the two-thirds of the clavicle.

-All the fascia unite almost immediately after the origin.

3-Arctomys (= Marmota)

Origin

1-On the clavicle, the deltoid presents two fascia. There is actually a doubling of the clavicular deltoid. The superficial fascia takes origin on half of the external border and a little on the anterior surface of the clavicle. The profundus fascia is placed under the superficial and extends a little on the posterior surface. The origin of both the fasia is fleshy.

2-On the posterior border of the acromion, the origin 
is by tendinous fibres.

$3-0 n$ the spine, the origin is on the two-thirds of the length.

4-There is a small fascia on the aponeurosis of the $\mathrm{m}$. infraspinatus.

Insertion - The spinal and the acromial fascia unite towards their insertion. They terminate in the lower part of the superior one-third of the humerus. The profundus fascia on the clavicle is inserted by the side of the insertion of the spinal and the acromial deltoids. The superficial clavicular fascia passes on to the fore-arm where it is inserted on the ulna.

The nerve of the clavicular deltoid divides into two branches. A branch penetrates the profundus fascia and crosses over to the superficial. The other branch is destined to the profundus fascia itself.

4-Spalax -On the external border of the clavicle the deltoid arises on almost whole of the length. Towards the sternal extremity of the clavicle the origin seems to curve on itself. It may represent the vestiges of the original double clavicular fascia.

-On the acromion and the spine, the origin is on the whole of the posterior border.

-All the fascia unite immediately after their origin.

5-Dipus -The clavicular fascia extends on the two-thirds of the external border of the clavicle.

-All the fascia unite immediately after their origin.

-In one specimen, the acromial fascia was seen not only on the acromion but also on the quarter of the length of the external border of the clavicle.

6-Atherura - The spinal fascia arises on the whole length of the spine.

- The acromial and the spinal fascia are closely united.

- The clavicular fascia extends on the half of the external border of the clavicle. It meets the scapular deltoid towards its middle.

7-Eliomys - The deltoid of Eliomys resembles that of the Atherura.

8-Ondatra -like that of Atherura with the following differences :-There is a small fascia on the aponeurosis of the $m$. infraspinatus. 
-Connective tissue separates the origin of the three fascia of the deltoid.

- The origin of the clavicular deltoid extends on more than the half of the external border of the claviele.

- Some fibres of the acromial trapezius are inserted on the acromial fascia of the deltoid.

9-Castor - Three fascia of the deltoid are closely united.

-The spinal fascia takes origin on the scapular spine as well as on a median spinal tubercle.

\section{Discussion}

The deltoid of the Rodentia does not present any characteristic features. It has the three usual parts and shows functional adaptations of various kinds. As regards phylogeny two atavistic features

Clavicule

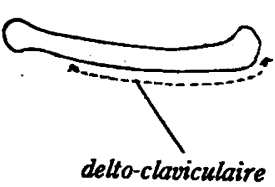

Humérus
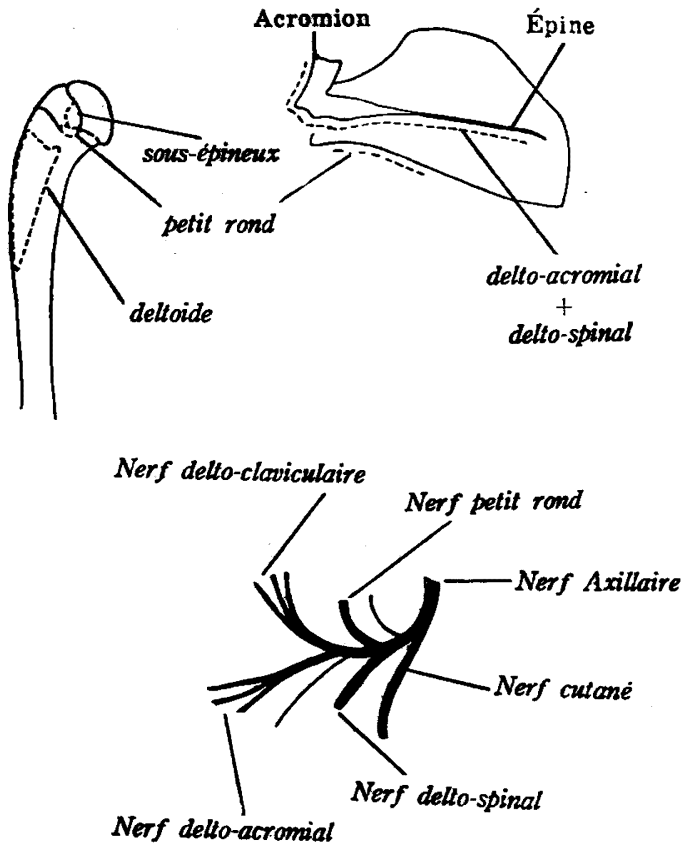

PTEROMYS

Fig. 1. 


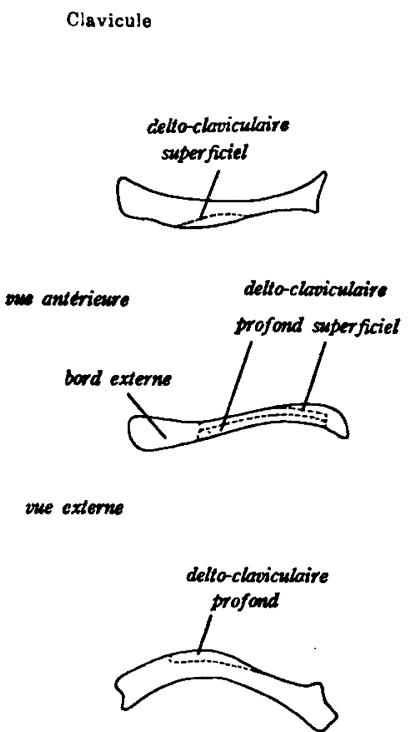

vine postérieure

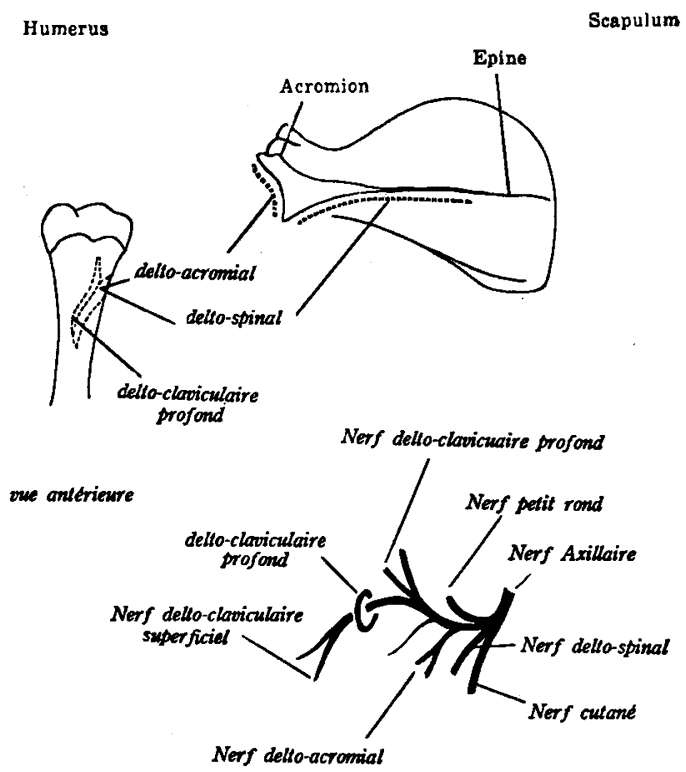

ARCTOMYS

Fig. 2.

found exceptionally in Ondatra and Dipus suggest origin from the early insectivore ancestors at about the same time as the marsupials. In Dipus, the origin of the acromial deltoid was found both on the acromion and the clavicle-a feature found only among the Insectivora ;in Ondatra, some fibres of the acromial trapezius were found inserted on the acromial deltoid as in Marsupialia. Leaving aside the functional importance of these features, they are quite suggestive of the early insectivore affinities.

The subdivisions Duplicidentata (Lagomorpha) and the Simplicidentata do not show distinguishing features of an ordinal status. The difference lies only in the presence of a simple deltoid tubercle in one (Duplicidentata), and the hook like version of the same in the other (Simplicidentata). Further, three parts of the deltoid are fused in the Duplicidentata, while in Simplicidentata they show various degrees of fusion.

Functionally the deltoid of the Rodentia presents interesting cases of adaptations as follows :-

1-Arctomys-presents a clear example of the doubling of the clavicular deltoid among the mammals, though such a feature has been reported 
Humérus

Scapulum

wue antérieure

vue esterne
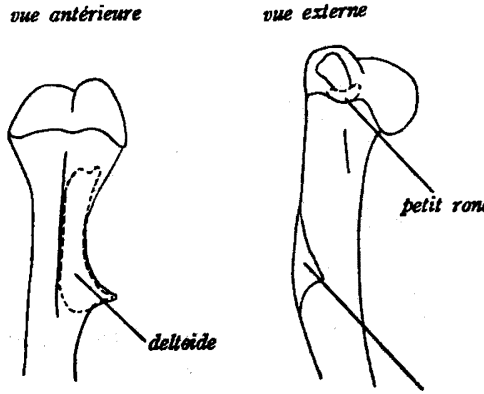

tubercle deltaidien
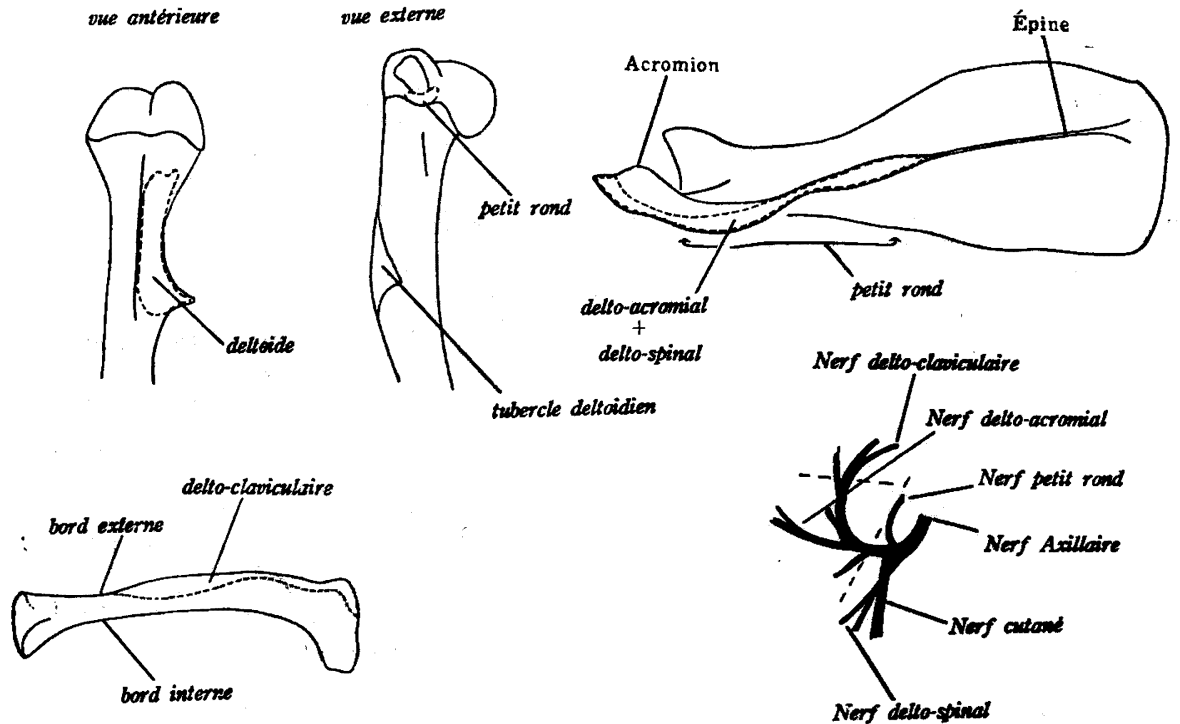

Clavicule oue posttriewre

CASTOR

Fig. 3.

in Spermophilus (P a r S o n s, 1894-96) and in the Monotremes (M c$\mathrm{k}$ a y, 1894-95). The innervation is characteristic and separate for each part in the Marmota (see figure) while in the Monotremes it is only a difference of fleshy and the tendinous fibres; the innervation of each part being without any individuality. The profundus fascia is quite normal but the superficial one is a scansorial adaptation, as the latter is inserted on the fore-arm. Such a condition is found in Bradypus, where the deltoid gives a slip (clavobrachialis; Mille r 1935) to the flexor muscles of the fore-arm. Other similar examples are presented by the insertions of the mastoido-humeral in some ungulates and carnivores-most of them showing typical cursorial and scansorial adaptations. Marmota lives in the mountainous regions and consequently quite action with power has been combined to meet the situation and the strain. During climbing, the superficial and profundus fascia keep the fore-arm flexed and the arm fixed, while the others will swing the weight of the body upwards.

2-Spalax-The Rodent mole, Spalax has the normal disposition of the deltoid parts. Apparently it has not undergone important modifica- 
tions as in the case of typical insectivoran moles. All the same it shows a great development of the $\mathrm{m}$. teres minor and the spinal deltoid. The length of the scapule has increased while its width is reduced-a characteristic feature of the fossorial life.

3-Hydrochaerus-The clavicle is exceptionally missing in Hydrochaerus among the Rodents. Consequently a mastoido-humeral is present as in the ungulates and the carnivores. Its insertion in the lower part of the humerus points to a cursorial adaptation.

4-Pteromys-The three parts are of the deltoid are fused in Pteromys. The origin and insertion are quite extensive in response to the volant adaptation. The disposition of the deltoid is such that an earlier stage of brachiation of the trees can be safely excludes. It is a point of strong contrast with the Megachiroptera. Some resemblance with the Microchiroptera, Petaurus, Petauroides and Cynocephalus is however noteworthy.

\section{Summary}

The deltoid musculature of 9 genera of the Rodentia is described on a comparative basis. The possible phylogenetic and adaptational features are also pointed out.

\section{Acknowledgements}

I am greatly obliged to professors J. Millot, J. Anthon and C. Devillers of Paris under whose guidance the work was carried out. I am equally grateful to Professor D. S. S h r i v a s t a va of Saugar University who helped me in various ways and encouraged me to publish the work in English, the original manuscript being in French. A list of English equivalents and other synonyms is provided to facilitate the use of the figures where some French names have been used.

\section{Bibliography}

A le $z$ a is, H. 1900. Contribution à la myologie des Rongeurs- Thèse presentée à la Faculté des Sciences de Paris.

Cuvier, G. 1835. Lecons d'Anatomie Comparée, Paris.

de Myologie.

Gr a s sé, P. P. 1954-55. Traîté de Zoologie, Tome.XVII, Mammifères. Paris. 
Gre gory, W.K. 1910. The orders of mammals. N. Y. Bull. Amer. Mus. Nat. Hist. $27: 1-524$.

Holl ig e r, C. D. 1916. Anatomical adaptations in the thoracic limb of the California Pocket Gopher and other rodents. Berkeley Univ. Cal. Pub. Zool. 13: 447-494.

How e 1 1, A. B. 1937a. Morphogenesis of the shoulder architecture. Part V. Monotremata. Quart. Rev. Biol. v. 12 : 191-205.

1937b. Mophogenesis of the shoulder architecture. Pt. VI. Therian mammalia ibid. $12: 440-463$.

Mck a y, W. J.S. 1894-95. The morphology of the muscles of the shoulder-girdle in monotremes. Proc. Linn. Soc. New SO. Wales, 9 : 263-369.

Parsons, F. G. 1894. On the myology of the sciuromorphine and histrico-morphine rodents. Proc. Zool. Soc. London. pp. 251-296.

1896. An account of the myology of the Myomorpha together with a comparison of the muscles of the various suborders of rodents. Proc. Zool. Soc. London. pp. 159-192.

Peterka, H.E. 1936. A study of the myology and oesteology of Tree-Sciurids with regard to adaptation to arboreal, glissant and fossorial habits. Trans. Kans. Acad. Sc. 39: 313-332.

S a b a n, R. 1954. Phylogenie des Insectivores. Bull. du Mus. d'Hist. Nat. Paris No. 3. $\mathrm{S}$ i m p s o n, G. 1945. The principles of classification and a classification of mammals. Bull. Amer. Mus. Nat. Hist. t. 85.

W e ber, M. 1904. Die Saugetiere. Jena. Gustav Fischer.

W ind le, B. C. A. and Pars ons, F. G. 1898. The myology of the terrestrial carnivora. Proc. Zool. Soc. London. pp. 152-186.

and 1901. On the muscles of the ungulata. Pt. I Proc. Zool. Soc. London. pp. 656-704.

W ood, A. E. and Wh it e, R. 1950. The myology of the Chinchilla. J. Morph. Philadelphia. $86: 547-597$.

English Equivalents of the French terms and other synonyms referred to in the figures and the text.
m. deltoide :
m. deltoideus, deltoid
m. delto-acromial :
m. delto-claviculaire :
m. acromial deltoid
m. clavicular deltoid;
m. deltoideus parsclavicularis;
m. cleido-deltoid
m. delto-claviculaire profond:
m. clavicular deltoid pars profundus
m. delto-claviculaire superficial:
m. clavicular deltoid pars superficialis
m. sous-épineux :
m. infraspinatus
m. petit rond :
m. teres minor
m. mastoido-huméral :
m. mastoido-humerien;
m. cephalohumeralis
Nerf axillaire :
Nerve axillaris
Nerf du delto-claviculaire:
Nerf du delto-acromial :
Nerf du delto-spinal:
Nerf cutané :
Nerve to the $\mathrm{m}$. delto-clavicular
Nerve to the m. delto-acromial
Nerve to the $m$. delto-spinal
Nerve cutaneous (Nervus cutaneous brachii lateralis)
Nerf du petit rond:
Nerve to the $m$. teres minor 
Clavicule :

\section{Epine:}

Tubercle deltoidien:

Vue antérieure:

Vue postérieure:

Vue externe:

Bord externe, bord interne de la clavicule:

In the diagrams the following views are shown except when indicated otherwise :-

Scapula-lateral view

Humerus-external view

Clavicle-anterior view (antero-extern). clavicle

spine of the scapula

deltoidian tubercle

anterior view

posterior view

external view

external, internal border of the clavicle 